\title{
Retraction Note to: Theoretical research of self-excited oscillations in transmitters for auxiliary motion of a tool machine using a nonlinear model
}

\author{
Milan Cvetković $^{1} \cdot$ Slavica Cvetković ${ }^{2}$
}

Published online: 24 August 2017

(C) The Brazilian Society of Mechanical Sciences and Engineering 2017

Retraction Note to: J Braz. Soc. Mech. Sci. Eng.

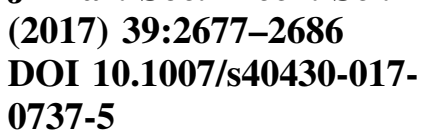

The Editor in Chief retracts this article (https://link. springer.com/article/10.1007/s40430-017-0737-5) in accordance with COPE guidelines because of unresolved issues relating to authorship. The article shows evidence of irregularities in authorship during the submission process and therefore the authorship of this paper cannot be established.

The online version of the original article can be found under doi:10.1007/s40430-017-0737-5.

Milan Cvetković

smijoc@yahoo.com

1 MSc Quantitive Finance, ETH Zurich \& University of Zurich, Zurich, Switzerland

2 Faculty of Mechanical Engineering, University of Pristina, Pristina, Kosovo, Serbia 